\title{
CLINICAL AND ELECTRO-ENCEPHALOGRAPHIC STUDIES OF PRISONERS CHARGED WITH MURDER
}

\author{
BY \\ D. STAFFORD-CLARK and F. H. TAYLOR \\ From the Maudsley Hospital and H.M. Prison, Brixton, London
}

During the past ten years a number of papers* have been published dealing with the relationship between antisocial behaviour and electro-encephalographic abnormality. The subjects of these enquiries have ranged in degree of behavioural instability from truants to aggressive recidivists in prison, and in ages from childhood to the late forties. With one exception (Gibbs and others, 1945), the results both in studies of children and of adults, suggest a significantly increased tendency for the electro-encephalographic records to be abnormal in subjects whose behaviour has brought them consistently into collision with society. The abnormalities noted are by no means specific, and their incidence ranges from 34 per cent. (Gibbs and others, 1942) to 82 per cent. (Hill and Watterson, 1942).

Since 1942 the opportunity has been taken to record the electro-encephalogram of sixty-four prisoners facing charges of murder; at first the selection of these subjects was governed by the wishes of the prison authorities or of those responsible for the prisoner's defence; but in the past two years the principle has been extended so that the latter part of the present series of cases represents a consecutive unselected sample of prisoners on a capital charge.

\section{Method of Investigation}

Full personal and family histories were obtained from each of the sixty-four prisoners, as well as details of the charge and trial proceedings. They were combined in every instance with a routine physical examination, an examination of mental state, and an electro-encephalogram. Subsequently, and before the electro-encephalographic records were studied at all, the cases were assessed on a purely clinical basis in the light of all the available information, and grouped under one of five headings to be described. Finally, in each case, the electro-encephalogram was analysed, and the records grouped and compared with the results of the clinical assessment.

\section{Clinical Material}

The sixty-four prisoners consisted of fifty-eight men and six women. The youngest was a boy of 14 (Case 14), the eldest a man of 60 (Case 54). In not all was the charge of murder proved ; in fifteen cases it was reduced to one of manslaughter, and three were found not guilty. Fifteen of the prisoners were ultimately considered to be guilty but insane, insane on arraignment, or insane after a statutory enquiry. Fourteen were executed.

\section{Details of Investigation}

The basis of clinical assessment of the five groups of cases was as follows.

Group 1 consisted of cases in which the killing had been incidental to the commission of another crime or had been in self defence. Cases in which harm had been intentional, as for example a blow on the head during a robbery, were not included.

\section{EXAMPLES}

Cases 47 and 63.-Two young men, finding themselves in financial difficulties, decided to break into a shop and steal therefrom any money they could find. They observed the times at which the old man in charge went to lunch, and lying in wait for him on his return they overpowered him and gagged him with a piece of curtain material. After an unsuccessful search for money they left the shop hurriedly and the old man was found some hours later suffocated by the gag.

Case 62.-A young man had separated from his wife following frequent quarrels with her because of her allegedly immoral life. He met her one day in the street, a quarrel ensued and she attacked him with a knife. In the struggle which followed she was stabbed in the chest and died.

Group 2 included all cases in which it was considered that there was a clear motive for killing or in which death followed intended violence during the commission of another crime.

\section{EXAMPLES}

Case 32.-A young soldier, returning home after more than a year overseas, found his wife in a maternity 
hospital about to be confined. When he visited her, accompanied by her mother and sister, she ignored him completely and refused to speak to him; he asked to be left alone with her for a short time and then strangled her.

Case 43. - A man of 50 years of age, who had always been a heavy drinker, was constantly being nagged because of this by his wife. One evening she was particularly critical and had been chiding him all night. As he returned from the lavatory he noticed a hammer and seizing it he struck his wife several blows on the head which resulted in her death.

Group 3 included those cases in which the crimes were apparently motiveless or in which the motive was very slight.

\section{EXAMPLES}

Case 1.-A young man of 25 years of age had been keeping company with a girl of his own age for some time. He had an exemplary war record and the couple were on the very best of terms. There had been occasional sexual intercourse and no major quarrels. On one occasion, for no apparent reason, he had seized her by the throat but had relaxed his grip without harming her. She had agreed to forget the incident and to continue their acquaintanceship. On the night of the murder they had spent the evening together listening to the radio at his home. No sexual relations had taken place nor had any sexual advances been made. As the girl rose to go he suddenly seized her by the throat and strangled her, placing the body under the bed and then notifying the police.

Case 10.-A countryman of 26 years of age had been associating with an Irish domestic servant as a result of which she became pregnant and gave birth to a child. $\mathrm{He}$ was in love with the girl and wished to marry her but there were religious differences. They continued to discuss arrangements amicably and it was agreed that though they would marry in the Roman Catholic Church he would not change his religion. Having met the girl one evening to discuss marriage arrangements, he suddenly and without any warning felled her with a heavy piece of wood and stabbed her in the neck with his clasp knife.

Group 4 consisted of those persons who were charged with murders in which there was a strong sexual element; only those cases were included, however, in which sexual activities of some kind occurred actually at the time of the murder.

\section{EXAMPLES}

Case 38.-A young sailor, much the worse for alcohol, accosted a much older woman and sexually assaulted her in a lonely spot. Her body was found as it had been left at the time of intercourse and she was found to have been strangled. She had also been robbed but most of the articles taken had been subsequently discarded indiscriminately.

Case 55.-A man aged 31 years had a paramour of 48 years, a widow with an adult daughter and adolescent son. Following one of his visits to the house the thre occupants were all found strangled. Both women we naked and showed signs of sexual interference; in the case of the younger woman intercourse had apparent $\bar{b}$ occurred after death and her pubic hair had beew violently torn out. The boy was badly mutilated and his genitals had been amputated and placed in his mother? mouth.

Group 5.-The last group consisted of those persons who were found unfit to plead or guilty but insane at their trials or who were subsequently found to be insane at a Statutory Enquiry. One caso (Case 10) was included in Group 3 rather than in this group because no evidence was given at the trial that he was insane and there was no suggestion at any time during the period of observation that he was insane. As the result of an eloquent speect by his counsel, however, a sympathetic jury found him to be guilty but insane.

\section{ExAMPLES}

Case 39.-A young man had not felt well and refused to go to work. His mother rebuked him and he fellede her with a flat iron and carried her body to the cellar. On reception he was confused, depersonalized, and delusions of persecution. There was thought-blocifng and poverty of affect and he was a clear case of schazor phrenia.

Case 11.-A young man of 28 years was received state of excitement and suffering from delusions thath was being drugged and that all his strength was be्भin drawn out of him through his penis. He thought his uncle was responsible and he killed him with a iron. Whilst under observation he had many epileptre attacks which were followed by excitement and con fusion.

On the basis of this grouping the 64 cases unde consideration were divided as follows :

$\begin{array}{cccc}\text { Group 1 } & \ldots & \ldots & \text { Cases } \\ \text { Group 2 } & \ldots & \ldots & 11 \\ \text { Group 3 } & \ldots & \ldots & 15 \\ \text { Group 4 } & \ldots & \ldots & 8 \\ \text { Group 5 } & \ldots & \ldots & 14 \\ & & & - \\ & \text { Total } & \ldots & 64\end{array}$

\section{Investigation of Electro-encephalograms}

The electro-encephalograms (EEG) were obtaine $\AA$ mainly with a Grass 3-channel standard electro? encephalograph using ink-writing oscillographs although a few of the cases were examined with atp Ediswan 6-channel apparatus. Bipolar electrodes. were used in all cases, records being obtained fronn serial positions in antero-posterior and transverse planes of the head. All subjects were examine after twelve hours' fasting. The total recording times 
was never less than thirty minutes. At the end of the recording, each subject was induced to overbreathe for a further period of three minutes, and, in the event of significant alteration in the E.E.G., blood was taken for estimation of the sugar concentration. The subject was then given $100 \mathrm{~g}$. of glucose by mouth and the overbreathing test repeated after thirty minutes, the blood sugar level being again estimated. In the assessment of results, the E.E.G. response to overbreathing was not by itself considered significant as a criterion of abnormality. The E.E.G.s have been divided into four groups, reflecting the degree of abnormality. These have been called " normal," " mild unspecific," " severe unspecific," and " specific, focal, or epileptic abnormality."

Normal Electro-encephalograms.-E.E.G.s have been classified as normal under the following circumstances. A dominant frequency of 8 to $13 \mathrm{c} / \mathrm{sec}$. present in the 'post-central areas of the head, which tends to "block" to visual attention stimuli, such rhythm being present from 5 to 100 per cent. of the time and symmetrical on the two hemispheres in respect to frequency, amplitude, and spread; however, slightly greater spread and amplitude of this rhythm on the right side was accepted as normal in young persons. Activity at 14 to $30 \mathrm{c} / \mathrm{sec}$. of low voltage, having symmetrical distribution and appearance in the precentral areas was often present. No record was regarded as normal within the age range studied in which activity at less than $4 \mathrm{c} / \mathrm{sec}$. was seen as a discrete rhythm. A small amount of activity at 4 to $7 \mathrm{c} / \mathrm{sec}$. in the central and temporal areas, particularly in a transverse electrode placement was accepted as normal provided such activity did not constitute the dominant activity in the record, and was not seen to have paroxysmal occurrence or to have an amplitude exceeding that of the 8 to $13 \mathrm{c} / \mathrm{sec}$. activity seen in the same part of the record. As already stated the response of the E.E.G. to three minutes' overbreathing was not alone considered as a criterion, provided such changes as occurred were symmetrical on the two sides in respect to frequency, amplitude, and spread, and, of course, provided no specific epileptic wave forms appeared (see below). However, the marked development of high voltage slow wave activity at high levels of blood sugar (more than $130 \mathrm{mg}$. per cent.) constituted a criterion of abnormality of the mild unspecific type (Heppenstall, 1944).

Mild Unspecific Abnormal Electro-encephalograms.Records in which, in addition to the normal appearances of 8 to $13 \mathrm{c} / \mathrm{sec}$. activity in the postcentral areas, and possibly 14 to $30 \mathrm{c} / \mathrm{sec}$. activity in the precentral areas, other activity was present, in most instances rhythms in the 4 to $7 \mathrm{c} / \mathrm{sec}$. range, but in excess of that seen in the "normal" group. Records in which rhythm of this frequency (theta) dominated the traces from the frontal, central, or temporal areas were included in this group.

Severe Unspecific Abnormal Electro-encephalograms.In this group were included the following abnormalities.
A dominant postcentral rhythm at less than $8 \mathrm{c} / \mathrm{sec}$. (no case of such rhythm at more than $14 \mathrm{c} / \mathrm{sec}$. was encountered). Paroxysmal high voltage 14 to $30 \mathrm{c} / \mathrm{sec}$. activity or at less than $8 \mathrm{c} / \mathrm{sec}$. in any region, such activity being symmetrical on homologous areas of the head. The presence of activity seen as a discrete rhythm (that is, amplitude greater than rhythms of normal frequency) at less than $4 \mathrm{c} / \mathrm{sec}$.

Specific, Focal, or Epileptic Abnormal Electro-encephalograms.-In this group were included the following abnormalities, which are additional to any described under previous headings : gross asymmetry of the rhythms on the two hemispheres, in respect to frequency, amplitude, or distribution ; the presence of abnormal activity-slow, fast, transient, "spike" or "sharp" wave located to a focal area by the method of phase reversal for the potentials seen in two channels connected in series to a common electrode ; or the presence of $3 \mathrm{c} / \mathrm{sec}$. wave and spike activity or variants of these complexes, seen either as "slow spike and waves" or mixed slow waves and multiple spikes.

TABLE I

\begin{tabular}{|c|c|c|c|c|c|c|c|}
\hline \multirow{2}{*}{\multicolumn{2}{|c|}{ E.E.G. }} & \multicolumn{5}{|c|}{ Group } & \multirow{2}{*}{ Total } \\
\hline & & 1 & 2 & 3 & 4 & 5 & \\
\hline $\begin{array}{l}\text { Normal } \\
\text { Mild unspecific } \\
\text { Severe unspecific } \\
\text { Specific, focal, } \\
\text { epileptic ... }\end{array}$ & $\begin{array}{l}\ddot{ } \\
\ddot{o} \\
\text { or } \\
\cdots\end{array}$ & $\frac{10}{1}$ & $\begin{array}{r}12 \\
2 \\
- \\
2\end{array}$ & $\begin{array}{l}4 \\
5 \\
4 \\
2\end{array}$ & $\begin{array}{r}4 \\
3 \\
- \\
1\end{array}$ & $\begin{array}{l}2 \\
7 \\
2\end{array}$ & $\begin{array}{r}32 \\
17 \\
7\end{array}$ \\
\hline Total & $\therefore$ & 11 & 16 & 15 & 8 & 14 & 64 \\
\hline
\end{tabular}

\section{Results}

The results of the electro-encephalograms in each of the five groups are shown in Table I.

Table II gives more detailed results, showing individual cases and indicating any significant family or personal history, together with the final verdict and disposal.

A study of the results indicates at once the preponderance of normal over abnormal E.E.G.s in Groups 1 and 2, whereas in the case of unmotivated crimes (Group 3 ) the reverse holds good. The only subject in Group 1 (47) who had a severe unspecific abnormality in his E.E.G. was a man of 22 years of age who had suffered in childhood from osteomyelitis of the left arm; thighs, and ribs and had been severely incapacitated thereby. He was sensitive about his disability and of very immature personality. The E.E.G. was, in fact, the type which might have been found in an unstable adolescent. Two of the abnormal E.E.G.s in Group 2 were specific in character. Case 53 had a history of head injury on two occasions and the E.E.G. showed a focal abnormality in the left hemisphere. Case 46 


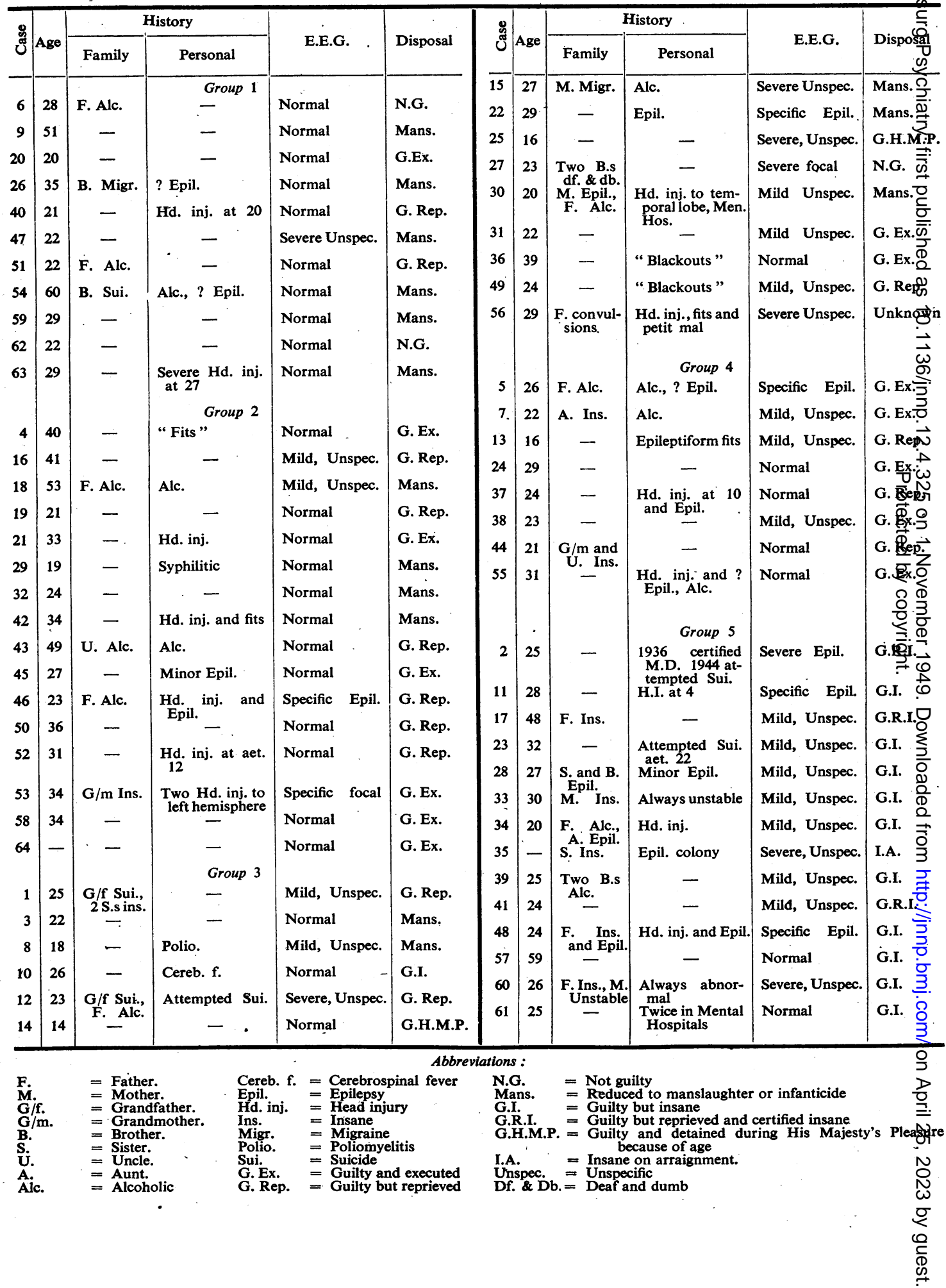


suffered from traumatic epilepsy and had a specific epileptic E.E.G. Two other subjects (Cases 16 and 18) had mildly abnormal unspecific E.E.G.s, and it is interesting that in each case the murders had very poor motives and might possibly have been included in Group 3. One murdered a prostitute, allegedly because she stole his wallet, though at the trial it was suggested that he had robbed her ; the other murdered his paramour on the flimsiest of pretexts of jealousy. Reconsideration of the four men with normal E.E.G.s in Group 3 (Cases 3, 10, 14, and 36)

TABLE III

\begin{tabular}{|c|c|c|c|c|c|}
\hline & & \multicolumn{2}{|c|}{ Record } \\
\hline & & & & Normal & Abnormal \\
\hline Epilepsy ... & .. & .. & 5 & 0 & 5 \\
\hline Schizophrenia & .. & .. & 3 & 1 & 2 \\
\hline Depression & .. & .. & 3 & 1 & 2 \\
\hline \multicolumn{3}{|c|}{ Psychopathic personality } & 2 & 0 & 2 \\
\hline Paranoia & .. & .. & 1 & 0 & 1 \\
\hline
\end{tabular}

did not reveal that they had been misplaced in the group, for in every case the murder appeared to be completely without motive of any real strength.

While results in Group 4 may be too few for significance, the eight cases being equally divided between normal and abnormal, Group 5 showed a very high proportion of abnormal records. In order better to appreciate the type of cases encountered in Group 5, the final diagnoses are given in Table III.

\section{Discussion}

The marked preponderance of abnormal records in Groups 3 and 5 (73 per cent. and 86 per cent. respectively) suggests strongly that whatever the nature of the cerebral dysfunction which such abnormal records indicate, it is significantly correlated with a capacity to commit violent acts of an apparently motiveless character. These cases include not only aggressive psychopaths such as Case 31, a man of 22 who battered to death with a hammer a woman who asked him to stop fooling about with the lights, following this by killing with the same hammer the child of his victim, both murders taking place in the presence of his wife ; they include also individuals who are clinically apparently perfectly normal : Case 1, already quoted as an example of Group 3, being one. In both these cases the abnormality of the E.E.G. was regarded as unspecific but definite. It is of interest that Group 3 cases as a whole exhibit a higher percentage of abnormal records even than Hill and Watterson's (1942) aggressive psychopaths.
The still higher proportion of abnormal records in Group 5 may be accounted for by the fact that five of them were epileptics and a further two grossly aggressive psychopathic personalities, with characteristic records.

In contrast, Group 1, the " accidental murder" group contains less than 10 per cent. of abnormal records, approximating closely to the proportion found in the general population (Williams, 1941), while Group 2-the motivated group-contains 25 per cent. of abnormal records which may correspond to the 34 per cent. found in a group of one hundred unselected criminals by Gibbs and others in 1942, and to the 31 per cent. quoted by the same writers for the murderers in this group after they had enlarged it by selection to include seventy-five men convicted of this crime. It compares also with the figure of 26.7 per cent. for the normal prison population given by Silverman (1943).

Rosanoff (1943), in a clinical study of thirty consecutive cases of men convicted of murder, diagnosed no fewer than fourteen of them as psychopaths. A study of his case histories reveals that the thirty would have fallen under our five group headings as in Table IV.

TABLE IV

GROUPING OF ROSANOFF'S CASES

\begin{tabular}{|c|c|c|c|}
\hline & & $\begin{array}{c}\text { Psycho- } \\
\text { paths }\end{array}$ & Total \\
\hline $\left.\begin{array}{ll}\text { Group } & 1 \\
\text { or } & \\
\text { Group } & 2\end{array}\right\}$ & $\begin{array}{l}\text { "Desperate, moti- } \\
\text { vated, or possibly } \\
\text { accidental killings" }\end{array}$ & $\begin{array}{l}8 \\
2 \\
1 \\
3\end{array}$ & $\begin{array}{r}18 \\
3 \\
2 \\
7\end{array}$ \\
\hline
\end{tabular}

It is, however, necessary to point out that Rosanoff defines psychopaths for this purpose as "so called habitual (or) professional . . . offenders." This is a definition so wide and general as to be of questionable value.

\section{Conclusions}

While it is generally acknowledged that unspecific abnormalities in the E.E.G. of a particular individual divorced from the relevant clinical picture and history, are valueless from a prognostic standpoint, there is another way of dealing with the evidence of investigations such as the one just described which may have more practical value.

The unsatisfactory nature of the psychiatric criteria commonly admissible in criminal justice for the assessment of an individual's culpability is well known ; moreover such assessment has ultimately to be made by a collection of laymen-the juryrather than by a trained observer. The courts are 
TABLE $\mathbf{V}$

FATE OF CONVICTED PRISONERS IN THIS SERIES

\begin{tabular}{|c|c|c|c|c|c|c|c|c|c|c|}
\hline & & $\begin{array}{c}\text { Guilty } \\
\text { and } \\
\text { executed }\end{array}$ & $\begin{array}{c}\text { Guilty } \\
\text { and } \\
\text { reprieved }\end{array}$ & $\begin{array}{l}\text { Not } \\
\text { guilty }\end{array}$ & $\begin{array}{l}\text { Reduced } \\
\text { to man- } \\
\text { slaughter }\end{array}$ & $\begin{array}{l}\text { Guilty } \\
\text { but } \\
\text { insane }\end{array}$ & $\begin{array}{c}\text { Insane } \\
\text { on } \\
\text { arraign- } \\
\text { ment }\end{array}$ & $\begin{array}{c}\text { Guilty } \\
\text { but } \\
\text { reprieved } \\
\text { and } \\
\text { insane }\end{array}$ & $\begin{array}{c}\text { Guilty } \\
\text { and } \\
\text { H.M.P. } \\
\text { (under 18) }\end{array}$ & 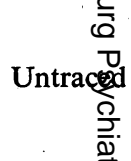 \\
\hline Group 1 & . & 1 & 2 & 2 & 6 & - & - & - & - & - \\
\hline Group 2 & . & 6 & 6 & 一 & 4 & - & - & - & - & - \\
\hline Group 3 & . & 2 & 3 & 1 & 5 & 1 & - & - & 2 & 1 \\
\hline Group 4 & . & 5 & 3 & - & - & - & - & 一 & - & - \\
\hline Group 5 & . & - & - & - & - & 10 & 1 & 3 & - & - \\
\hline Total & . & 14 & 14 & 3 & 15 & 11 & 1 & 3 & 2 & 1 \\
\hline
\end{tabular}

concerned, not with insanity as such, but with criminal responsibility (Kenny, 1936). Yet the possibility that in the E.E.G. we have at least an objective indication of innate propensities affecting responsibility-an indication moreover which is likely to be of maximal value in precisely those cases where clinical observation and the operation of reason are least able to elucidate the basis for the individual's actions-is one worthy of serious consideration. These cases may display no clinical evidence of insanity-either legal or medicalwhatever, yet unless, as seems highly unlikely, the correlation between apparently motiveless violence and an abnormal E.E.G. is purely coincidental, they are the very subjects who most of all require further investigation and study over a prolonged period, as well as detention for the protection of the community.

What, in fact, happened to those included in the present series may be seen from Table V, which is abstracted from the data included in the comprehensive Table II.

At a time when the public conscience is stirred over the issue of capital punishment, the potential value of the electro-encephalogram in providing the basis for a more enlightened attitude towards at least one group of criminals should not be underrated.

\section{Summary}

A clinical and electro-encephalographic study of sixty-four prisoners charged with murder suggests that a significant correlation exists between apparently motiveless crime and electro-encephalographic abnormality. While this abnormality is not specific, it has been found in over 70 per cent. of prisoners whose crimes appeared motiveless but who were otherwise clinically sane and normal. The indica- tions for further investigation of convicted prisonews falling into this group, and for their preventative detention, are discussed.

We are indebted to Dr. Denis Hill for access to material in his Department of Applied Electrophysionto in the Institute of Psychiatry, Maudsley Hospital for his analyses and comments on the original recofds; also to the Prison Commissioners for facilities for carrying out the investigation and for permissiom to publish it when completed; to Mr. A. Lubiro evaluation of statistical data, and finally to Profess $r$ Aubrey Lewis, under whose auspices on behalf od the Nuffield Foundation the work of one of us (D.Dwas performed.

\section{REFERENCES}

*Brill, N. Q., Seidemann, H., Montague, H., and Balser, B. H. (1942). Amer. J. Psychiat., 98, 494. *Brown, W. T., and Solomon, C. I. (1942). Ibid., 499.

*Gallagher, J. R., Gibbs, E. L., and Gibbs, F. A. (1949) Psychosomat. Med., 4, 134.

*Gibbs, F. A., Bagchi, B. K., and Bloomberg, W. (1948). Trans. Amer. Neurol. Assoc., 68, 87. (1945). Amer. J. Psychiat., 102, 294. $\overline{\overline{0}}$

Heppenstall, M. E. (1944). J. Neurol. Psychiat., n.\$. $7,112$.

*Hill, D., and Watterson, D. (1942). Ibid., n.s., 5, 47.0

*Jasper, H. H., Solomon, P., and Bradley, C. (1938). Amer. J. Psychiat., 95, 641.

Kenny, F. B. A. (1936). "Outlines of Criminal" Law, Fifteenth Edit. Courtney Stanhope Ltd., Cambridge University Press.

Knott, J. R., and Gottlieb, J. S. (1944). Arch. Neuröj. Psychiat., Chicago, 52, 515.

*Lindsley, D. B., and Cutts, K. K. (1940). Ibid., 1199.

Rosanoff, A. J. (1943). Amer. J. Psychiat., 99, 484.

Silverman, D. (1943). Arch. Neurol. Psychiat., Chicas, $50,18$. (1944). Ibid., 52, 38.

*Secunda, L., and Finley, K. H. (1942). 'New Engl. S্গ! Med., 226, 850.

*Williams, D. (1941). J. Neurol. Psychiat., n.s., 4, 2 涊 